\title{
Pseudoaneurysm of the pulmonary trunk after placement of an adjustable pulmonary artery banding device (FloWatch-PAB) in a patient with muscular ventricular septal defect
}

Ina Michel-Behnke, MD, ${ }^{a}$ Hakan Akintuerk, MD, ${ }^{a}$ Klaus Valeske, MD, ${ }^{a}$ Josef Thul, MD, ${ }^{a}$ Matthias Mueller, MD, ${ }^{\mathrm{b}}$ and Dietmar Schranz, MD, ${ }^{a}$ Giessen, Germany

ingle or multiple muscular ventricular septal defects (VSDs) with a significant left-to-right shunt require pulmonary artery banding $(\mathrm{PAB})$ in the first months of life. An optimized flow restriction can rarely be achieved or maintained over time. Conventional PAB carries the risk of pulmonary branch stenosis and damage to the vessel wall. In 2003, Corno and colleagues ${ }^{1}$ reported their first clinical experience of a completely externally adjustable banding device (FloWatch-PAB) to overcome these disadvantages. Recently, the results of a multicenter study were published, in which the device was judged to

From the Pediatric Heart Center and the Department of Anaesthesiology, Justus-Liebig University Giessen, Giessen, Germany.

Received for publication Feb 14, 2005; revisions received March 1, 2005; accepted for publication March 15, 2005.

Address for reprints: Ina Michel-Behnke, MD, Justus-Liebig University, Pediatric Heart Center, Department of Pediatric Cardiology, Feulgenstrasse 12, 35392 Giessen, Germany (E-mail: ina.michel-behnke@paediat.med.unigiessen.de).

J Thorac Cardiovasc Surg 2005;130:894-5

$0022-5223 / \$ 30.00$

Copyright $\odot 2005$ by The American Association for Thoracic Surgery doi:10.1016/j.jtcvs.2005.03.010 be safe and effective. ${ }^{2}$ We report on a patient presenting with a huge pseudoaneurysm of the pulmonary trunk after insertion of the FloWatch-PAB device.

\section{Methods and Results}

A 3-month-old boy with a body weight of $4.2 \mathrm{~kg}$ had heart failure caused by excessive pulmonary shunting through a 7-mm muscular VSD and secondary pulmonary hypertension. A FloWatchPAB device was inserted through a median sternotomy around the pulmonary artery trunk (Figure 1). The operation was uneventful, and immediately after the operation, the constriction of the banding was adjusted telemetrically to $50 \%$. The induced restriction of the pulmonary artery flow decreased the pulmonary artery pressure to $50 \%$ of the systemic arterial pressure, with a Doppler gradient of $66 \mathrm{~mm} \mathrm{Hg}$ in the pulmonary trunk.

Nine days after the operation, pericardial effusion had to be drained, and echocardiography demonstrated almost laminar flow in the pulmonary artery trunk. Telemetric adjustment to $90 \%$ closure of the device was not able to induce further restriction of the flow, as measured by means of echocardiography.

The patient continued to have excessive lung perfusion. Seven weeks after placement of the banding device, he presented with severe congestive heart failure and dyspnea. A chest $\mathrm{x}$-ray film revealed a huge aneurysm of the pulmonary artery trunk (Figure 2). He was sent

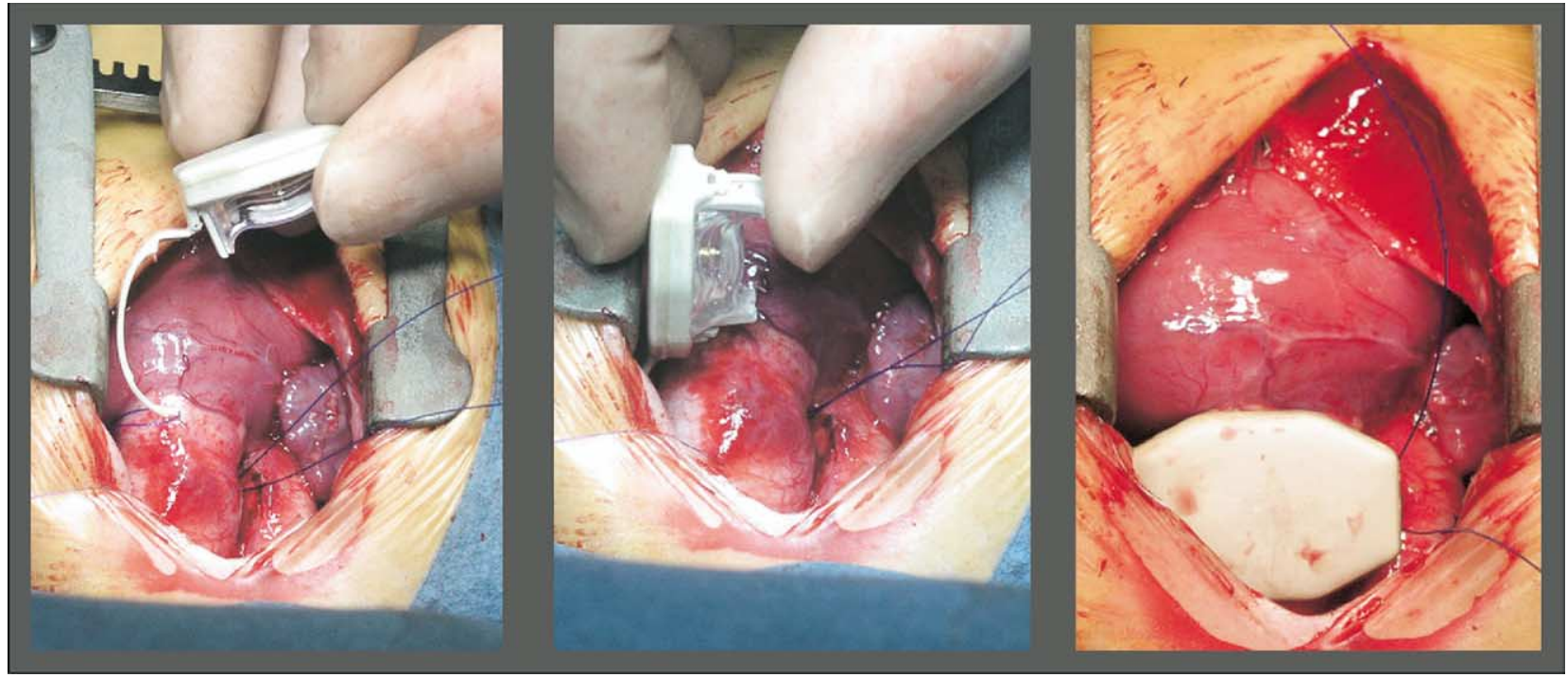

Figure 1. Placement of the FloWatch-PAB device around the pulmonary artery trunk. 


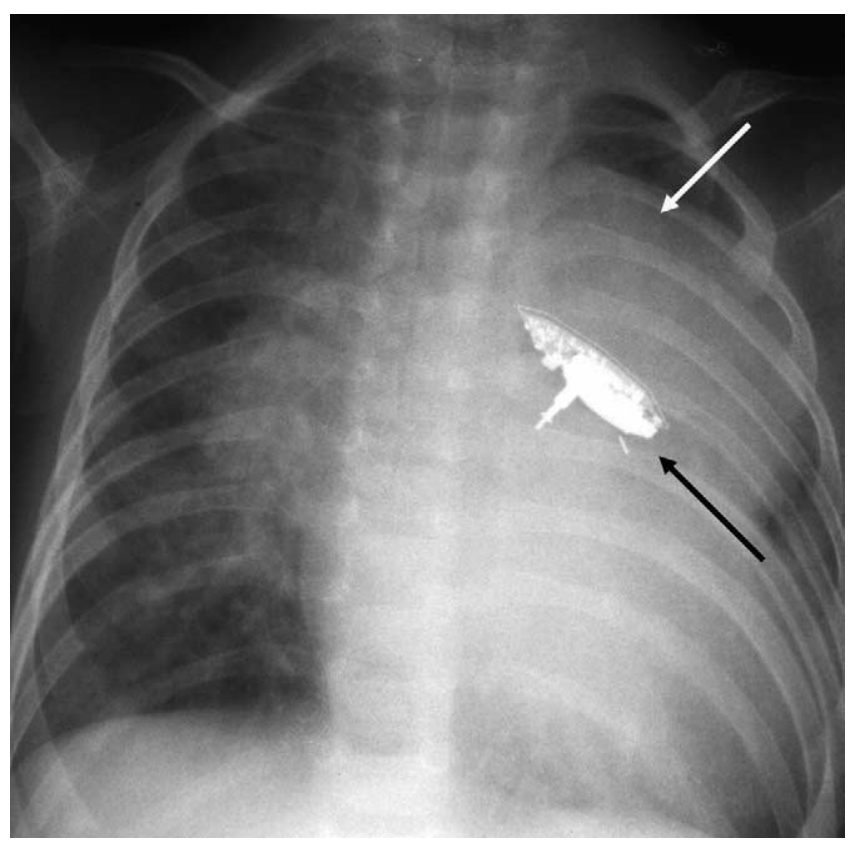

Figure 2. Chest x-ray film demonstrating a pseudoaneurysm of the pulmonary artery trunk (white arrow) 7 weeks after placement of a FloWatch-PAB device (black arrow).

for surgical intervention, during which the diagnosis of a pseudoaneurysm was confirmed. The banding device was found within the pulmonary artery trunk surrounded by a capsule preventing hemorrhage up to that time. The pseudoaneurysm was resected, and the device was removed. The tricuspid valve had to be incised to expose the VSD; thereafter, the defect could be closed through insertion of a patch, which was uneventful.

\section{Discussion}

In the past, efforts have been made to control pulmonary flow and pressure by using banding devices that were adjusted invasively. ${ }^{3,4}$ Fibrosis and even necrosis of the pulmonary artery were observed.
When Corno and colleagues ${ }^{1}$ reported their first clinical experience with a completely externally adjustable banding device (FloWatch-PAB), developed by EndoArt SA (Lausanne, Switzerland), it seemed that a dream had come true. The mechanism of controlling the width of the banding was realized through transmission of energy from an external control unit by means of radiofrequency waves. With this device, damage to the vessel wall of the pulmonary artery was not observed. ${ }^{5}$ In the patient presented here, the mechanism of rupture of the pulmonary artery with pseudoaneurysm formation is unclear but might have been due to a lesion set during preparation while the FloWatch-PAB was placed. The capsule that was visualized during removal of the device prevented bleeding. Retrospectively, the rupture of the pulmonary artery should have occurred 7 days after the first operation, when pericardial effusion was diagnosed. This also explains why the banding effect was lost, and continued left-toright shunting worsened the patient's clinical condition.

We share the same good experience as Bonnet and associates ${ }^{2}$ in 2 other patients in whom the banding worked perfectly, but nevertheless, this severe complication might occur and should be kept in mind regardless of the advantages the FloWatch-PAB offers. Careful preparation of the pulmonary trunk and smooth placement of the device around it seem essential to prevent aneurysm formation.

\section{References}

1. Corno AF, Bonnet D, Sekarski N, Sidi D, Vouhe P, Von Segesser LK. Remote control of pulmonary blood flow: initial clinical experience. J Thorac Cardiovasc Surg. 2003;126:1775-80.

2. Bonnet D, Corno AF, Sidi D, Sekarski N, Beghetti M, Schulze-Neick I, et al. Early clinical results of the telemetric adjustable pulmonary artery banding FloWatch-PAB. Circulation. 2004;II158-63.110(suppl II):

3. Leeuwenburgh BP, Schoof PH, Steendijk P, Baan J, Mooi WJ, Helbing WA. Chronic and adjustable pulmonary artery banding. $J$ Thorac Cardiovasc Surg. 2003;125:231-7.

4. Muraoka R, Yokota M, Aoshima M, Nomoto S, Kyoku I, Kobayashi A, et al. Extrathoracically adjustable pulmonary artery banding. J Thorac Cardiovasc Surg. 1983;86:582-6.

5. Corno AF, Sekarski N, Bernath MA, Payot M, Tozzi P, Von Segesser LK. Pulmonary artery banding: long-term telemetric adjustment. Eur J Cardiothorac Surg. 2003;23:317-22. 